\title{
Clinical profile of designer drug "Strox" intoxicated cases presented to Poison control center Ain Shams University, Egypt from first of January 2017 to end of January 2018
}

\author{
Mohy El-Masry and Salma Ibrahim Abdelkader ${ }^{1}$ \\ ${ }^{1}$ Poison Control Center, Forensic Medicine and Clinical Toxicology department, faculty of medicine, Ain Shams \\ University, Cairo, Egypt.
}

\begin{abstract}
Introduction: Drug addiction is considered one of the serious problems. Clinical profile of drug dependence is continuously changing taking new shape, new drugs and routes. From 2004, illicit drug manufacturers began to produce herbal smoking substances under a wide range of brand names. Recently over the past two to three years, the drug abuse market in Egypt was invaded by a new herbal preparation, called "Strox" that gained favor among abusers and rapidly spread. Aim of Study: to evaluate the strox toxicity cases including; the presenting symptoms and signs, the lines of treatment and highlight the outcomes secondary to strox exposure, also correlate the presenting clinical pictures with strox structure. Methodology: A cross sectional observational study carried out at Poison Control Center Ain Shams University (PCC-ASU). The study included all strox intoxicated patients presented to PCC-ASU from the first of Jan. 2017 to the end of Jan. 2018, and the obtained seized Strox packages screened by Gas Chromatography (GC). Results: there were 84 patients. The mean age was $25 \pm 9.8$ year. The median of delay time was 2-4 hours. Disturbed conscious level observed in $45 \%$ of patients, chest pain (37\%), shortness of breathing (32\%). Hypoxemia was evident in $65 \%$ of cases, associated with Hypercapnia and respiratory acidosis in $50 \%$ of cases. No observed changes regarding serum electrolytes, renal function or random blood sugar. ST segment depression and T wave inversion were reported in $6 \%$ of cases. All patients were admitted and received supportive treatment. Gas chromatographic analysis of some Strox packages revealed the presence of xylene, methylene dioxy methamphetamine, and trihexyphenidyl. Conclusion: Patients with Strox smoking presented with transient coma, hallucinations, impaired ventilation, and chest pain. The displayed picture was attributed to a mixture of xylene, MDMA, and the central anti-cholinergic trihexiphenidyl. The picture was confirmed by gas chromatography analysis of seized strox package.
\end{abstract}

Key words Addiction, Designer Drugs, Strox, Synthetic Cannabinoids

\section{Introduction}

$\mathrm{I}$ n Egypt, drug addiction is considered one of the serious problems to the community. It affects 1 young teenagers in the productive years and imposes considerable challenges to their families and friends, viewing the high risks of violence, crime, accidents, aggression, job firing, divorce, and rejection from the society and family (Abass et al., 2107). Clinical profile of drug dependence is continuously changing taking new shape, new drugs and routes. While barbiturates, amphetamine and benzodiazepines were leading the list of drugs of abuse in the eighties and nineties of the twentieth century, new drugs made appearance in the new century including tramadol, methylene dioxy methamphetamine MDMA and synthetic cannabinoids (SCs) (known as voodoo) in addition to the ever-present heroin and other opioids. Since then, the character of the drug of abuse changed as well. The designer drugs started to replace the conventional drugs of abuse. Newly designed chemicals (synthetic cannabinoids) acting on cannabinoid receptors pose the challenge of undetectability by drug screen and the higher potency and life threatening hazards. From 2004, illicit drug manufacturers began to produce herbal smoking substances under a wide range of brand names, e.g. "Spice", K2, vodoo (Aldlgan, 2016). These drugs are easily available via the internet, in smoke shops, and street markets. To escape law enforcement, these herbal incense products are often labeled "not for human consumption". The idea is spray of herbal product by psychoactive substances like synthetic cannabinoids compounds which are more potent than natural product and have higher affinity to bind $\mathrm{CB}_{1}$ and $\mathrm{CB}_{2}$ receptors and also other substances can be used to give various effects (Wilson-Hohler et al., 2016). Recently over the past two to three years, the drug abuse market in Egypt was invaded by a new herbal preparation, called "Strox" that gained favor among abusers and rapidly spread. Two types of Strox were identified; the green marjoram type and the other tobacco type are sprayed by active substance. Abusers of these preparations presented to the Poison control 
center of Ain Shams University (PCC-ASU) started in 2017. There are limited epidemiological data regarding this new substance and its complications developed after both acute and chronic exposure.

\section{Aim of the Study}

This work aimed to evaluate the strox toxicity cases to outline the presenting symptoms and signs, the lines of treatment and also highlight the outcomes secondary to strox exposure, and try to correlate the presenting clinical pictures with strox structure.

\section{Methodology}

Study design: This was a cross sectional hospitalbased observational study carried out at Poison Control Center Ain Shams University (PCC-ASU).

Inclusion criteria: The study included all patients of strox toxicity presented to PCC-ASU in the period from the first of Jan. 2017 to the end of Jan. 2018.

Ethical Considerations: An official permission was taken from the general director of the PCC-ASU. The approval of the Local Research Ethics Committee was obtained (Approval number: FMASU R 8/ 2018). Patient consent was waived because this was a retrospective study based on medical records. All personal data were kept anonymous to ensure confidentiality of records.

Data collection and study variables: In each case the following data were collected from the patients' medical records

- Socio-demographic variables including age and sex.

- Intoxication data: including route, place of exposure, type of congestions, and delay time.

- Clinical data (symptoms and signs).

- Investigations: they included all those were done for the patient like serial arterial blood gas analysis where Alveolar-arterial (A-a) gradient was calculated, ECG and chest X Rays.

- Lines of treatment received

- Outcome:

- All the patients were observed for short-term outcomes; that are either clinical improvement and discharge, or death.

The seized Strox packages were obtained from the patients presented to PCC-ASU and screened by Gas Chromatography (GC). Gas chromatography analytical detection was performed on different Strox packages after liquid extraction with methyl alcohol. Gas Chromatography (GC) instrument used was Dani 2000 GC, using FID detection, helium gas mobile phase and non-polar capillary column HP-1 (100\% dimethylpolysiloxane). Negative standards in the form of tobacco and marjoram were purchased from the market. Positive standards were used to confirm the screen.

Statistical method: Data were collected, revised, coded and entered to the Statistical Package for Social Science (IBM SPSS) version 20. The method of data presentation depends on the type of data.

\section{Results}

The total number of strox intoxicated patients received by the PCC-ASU during the study period was 84 patients, one of them was a two year old child accidentally exposed. The earliest reported cases of strox intoxication in the current study started during February 2017 but there was observed increase in their number during November 2017 till end of January 2018 (Figure 1).

The mean age of patients in the current study was $25 \pm 9.8$ years about $50 \%$ of them in age group between 20 and 29 years. Almost all patients, except one, were males. The main route of exposure was inhalation by smoking. Most of studied patients (77\%) presented with strox only without co-ingestion of other substance and only 23\% of patients presented with consumption of other substance with strox. Cannabis topped the list of co-ingestion accounting for $40 \%$ (8 cases). The street is the commonest place where strox was consumed. The median of delay time between exposure and presentation to PCC-ASU was 2-4 hours and most of patients (63\%) presented within 2 hours after exposure (table 1 ).

Table (2) and figure (2) show the physical findings observed in the current study where transient disturbed conscious level observed in 38 patients $(45 \%), 34$ of them the coma grade ranged between I to II by Reed's classification while the remaining 4 patients were in grade IV coma. Most (36 out of 38) of cases, regained consciousness within 3 to 6 hours. In only 2 cases ( $5 \%$ of this series), coma was prolonged to 1 day and was associated with mild to severe respiratory acidosis with cyanosis, respiratory distress with A-a gradients of 73 and $120 \mathrm{mmHg}$ (high as regard their age and $\mathrm{FiO}_{2}$ ).

The other central nervous system manifestations included convulsion that observed in $4.7 \%$ of patients. Agitation and hallucination observed in 20 patients (23.8\%). In $75 \%$ of patients (15 out of 20 cases) who initially presented with hallucinations and agitation, transient disturbed conscious level followed. All cases (who developed disturbed consciousness after agitation and hallucinations) rapidly \& spontaneously aroused from their coma within 3 to 6 hours except for one case presenting with agitated coma and hallucinations that lasted 24 hours. Hypercapnia and respiratory acidosis was evident in 10 out of 20 cases presented with hallucinations and agitation. $\mathrm{PaCO}_{2}$ was normalized after the acute episode that lasted 3 to 6 hours.

A 21-years- old patient was admitted with a history of convulsions presented with coma, sinus tachycardia 150 beats/minute, cyanosis, severe respiratory distress, and severe metabolic and respiratory acidosis (pH $6.9-\mathrm{HCO}_{3} 13 \mathrm{mEq} / \mathrm{l}-\mathrm{PaCO}_{2} 59 \mathrm{mmHg}-$ $\mathrm{PaO}_{2} 75 \mathrm{mmHg}$ on $\mathrm{FiO}_{2}$ 0.6). A-a gradient was 138 (normal for his age and $0.4 \mathrm{FiO} 2$ is $11 \mathrm{mmHg}$ ). Apart from mechanical ventilation support, he was treated supportively with empirical antimicrobials, IV bicarbonate and IV fluids. The patient had a favorable response, resumed his consciousness after 1 day and was weaned after 2 days.

As regard cardiovascular and respiratory manifestations; they included chest pain observed in $37 \%$ of patients, sinus tachycardia in $22.6 \%$, and hypertension in $10.7 \%$. Shortness of breathing, respiratory distress and tachypnea were the presentations 
in 33 patients (39.2\%). Hypoxemia was evident in 65\% of cases, associated with hypercapnia and respiratory acidosis in $50 \%$ of cases. Alveolar arterial (A-a) oxygen gradient was abnormally elevated in $46.4 \%$ of patients after considering age and $\mathrm{FiO}_{2}$, usually associated with tachypnea and respiratory distress.

Chest pain associated with inferior or inferolateral ischemic signs in the ECG of 5 patients (6\%); cardiac markers remained within the normal limits during hospitalization period. Further cardiac evaluation was undertaken for all ischemic cases after transfer to cardiology department. Half the patients presented with chest pain had hypoxemia and high alveolar arterial oxygen gradient. One patient had atrial fibrillation with controlled ventricular response, of transient nature that reverted to sinus rhythm before discharge. Chest pain, dyspnea and ischemic ECG signs weren't only related to old age but also noted in an 18 years old male patient. On oxygen 30\%, his A-a gradient was 61 (Normal for his age $=8.8 \mathrm{mmHg}$ ).

Regarding gastrointestinal manifestation; vomiting was noted in about $24 \%$ of patients (20 out of 84 patients) \& it was not related or associated with any of the neurological, cardiovascular or respiratory manifestations while a 2-years- old child presented with a history of accidental ingestion of the marjoram sprayed Strox, after initial lucid episode. Coma (of grade II) was associated with vomiting, hypertension and tachycardia. His ABG and laboratory investigations were normal with negative urine drug screening for tramadol, cannabis and other drugs of abuse. The child had an uneventful recovery and discharged after 1 day.
Regarding laboratory investigations; almost half of patients developed acute mild to moderate hypercapnia $(50 \%)$ with respiratory acidosis. No observed changes were evident in serum electrolytes, renal function or random blood sugar. In only six out of 84 patients, hyperglycemia $(140-190 \mathrm{mg} / \mathrm{dl})$ was recorded and it was mostly attributed to stress.

ECG of $6 \%$ of patients showed inferior wall or inferolateral ischemic signs in the form of ST segment depression and $\mathrm{T}$ wave inversion. These patients were transferred in Cardiac care settings for percutaneous coronary intervention and or evaluation. Only one patient developed transient rate controlled atrial fibrillation (AF).

All patients were admitted and received symptomatic and supportive treatment according to critical care guidelines, eleven patients (13\%) were admitted in intensive care unit (ICU) (Figure 3). Two patients needed mechanical ventilation for 1 to 2 days. The mean duration of hospitalization was $1.15 \pm 0.47$ days with range of 1 to 2 days (table 3 ).

Forty nine percent of patients in the current study were discharged after improvement of clinical condition, 35\% of patients were discharged against medical advice and $7 \%$ of patients were referred for further evaluation.

Gas Chromatographic testing was performed on both tobacco and marjoram based packages. Strox packages revealed the presence of xylene, methylene dioxy methamphetamine, and trihexyphenidyl (in some packages) among other non-identified substances. These substances were not detected in the negative tobacco and marjoram standards samples that were processed like nicotine and marjoram based Strox.

Table (1): Percentage of age, sex of patients, route and place of exposure, and type of co-consumed compounds in the current study:

\begin{tabular}{|c|c|c|c|}
\hline \multicolumn{2}{|c|}{ Variables } & $\begin{array}{c}\text { Number } \\
\mathrm{N}=\mathbf{8 4} \text { cases }\end{array}$ & Percent \% \\
\hline \multirow[b]{3}{*}{ Age (years) } & Mean \pm SD & \multicolumn{2}{|c|}{$25.10 \pm 9.81$} \\
\hline & Range & \multicolumn{2}{|c|}{$2-54$} \\
\hline & Age groups & $\begin{array}{c}{[2-19]} \\
{[20-29]} \\
{[30-39]} \\
{[40-54]} \\
\end{array}$ & $\begin{array}{l}30 \% \\
50 \% \\
10 \% \\
10 \% \\
\end{array}$ \\
\hline \multirow{2}{*}{ Sex } & Female & 1 & $1.2 \%$ \\
\hline & Male & 83 & $98.8 \%$ \\
\hline \multirow{2}{*}{ Route of intake } & Smoking & 83 & $98.8 \%$ \\
\hline & Oral & 1 & $1.2 \%$ \\
\hline \multirow{3}{*}{ Place of intake } & Street & 65 & $66.7 \%$ \\
\hline & Home & 24 & $24 \%$ \\
\hline & Unreported & 4 & $4.8 \%$ \\
\hline \multirow{5}{*}{ Type of Co-consumed substance } & Cannabis & 8 & $40.0 \%$ \\
\hline & Alcohol & 5 & $25 \%$ \\
\hline & Voodo & 2 & $10 \%$ \\
\hline & Tramadol & 3 & $15 \%$ \\
\hline & Opiate- clonazepam - Parkinol- & 2 & $10 \%$ \\
\hline \multirow{3}{*}{ Delay (hours) } & Median (IQR) & \multicolumn{2}{|c|}{$2(2-4)$} \\
\hline & Range & \multicolumn{2}{|c|}{$1-48$} \\
\hline & $\begin{array}{c}\leq 2 \text { hours } \\
>2<24 \text { hours } \\
\geq 24 \text { hours }\end{array}$ & \multicolumn{2}{|c|}{$\begin{array}{c}63 \% \\
29 \% \\
8 \%\end{array}$} \\
\hline
\end{tabular}

$S D$ : standard deviation, IQR: interquartile range. $N$ : number 
Table (2): Clinical findings presented in the patients during the current study:

\begin{tabular}{|c|c|c|c|}
\hline Clinical Findings & $\begin{array}{c}\mathrm{N} \\
\text { (total 84) }\end{array}$ & $\%$ & Note \\
\hline Tachypnea /SOB / Respiratory distress & 33 & $39.2 \%$ & \\
\hline $\begin{array}{l}\text { Bradypnea (impaired respiratory drive with } \\
\text { coma) associated with cyanosis }\end{array}$ & 2 & $2.4 \%$ & $\begin{array}{l}\text { Associated with deep coma, requiring } \\
\text { mechanical ventilation }\end{array}$ \\
\hline Hypertension (above 120 / 80 mmHg) & 9 & $10.7 \%$ & $\begin{array}{l}\text { Usually mild and associated with other } \\
\text { respiratory or neurologic manifestations }\end{array}$ \\
\hline Tachycardia ( $>90$ beats per minute) & 19 & $22.6 \%$ & Short lived, transient in nature \\
\hline Bradycardia & 2 & $2.4 \%$ & \\
\hline Disturbed conscious level & 38 & $45 \%$ & \\
\hline Agitation and Hallucinations & 20 & $23.8 \%$ & Were often followed with coma \\
\hline Motor seizures & 4 & $4.7 \%$ & \\
\hline Chest pain & 31 & $37 \%$ & \\
\hline Vomiting & 20 & $23.8 \%$ & \\
\hline Hypoxemia & 55 & $65 \%$ & $\begin{array}{l}\text { The most common clinical finding; } \\
\text { rapidly corrected by supplemental oxygen } \\
\text { in most cases }\end{array}$ \\
\hline Acute hypercapnia and respiratory acidosis & 42 & $50 \%$ & $\begin{array}{l}\text { Usually mild and transient in more than } \\
\text { half of these patients }\end{array}$ \\
\hline Elevated (A-a) $\mathrm{O} 2$ gradient (for age and $\mathrm{FiO2}$ ) & 39 & $46.4 \%$ & \\
\hline Ischemic signs on ECG & 5 & $6 \%$ & Mainly inferior or inferolateral \\
\hline $\begin{array}{c}\text { Atrial fibrillation (controlled Ventricular } \\
\text { response) }\end{array}$ & 1 & $1.2 \%$ & $\begin{array}{l}\text { Reverted spontaneously to sinus before } \\
\text { discharge }\end{array}$ \\
\hline $\begin{array}{c}\text { Cardiac markers } \\
\end{array}$ & - & - & Negative \\
\hline CT brain positive finding & 1 & & $\begin{array}{l}\text { Right thalamic and temporal hypodense } \\
\text { area in a } 25 \text { y old male consuming } \\
\text { synthetic cannabinoids in addition }\end{array}$ \\
\hline
\end{tabular}

SOB: shortness of breathing, $N$ : number, A-a alveolar-arterial oxygen gradient

Table (3): Hospital admission and the mean of the period of admission in the current study;

\begin{tabular}{|c|c|c|c|}
\hline \multicolumn{2}{|c|}{ Total number (84) } & Number & Percentage \% \\
\hline \multirow{2}{*}{ Hospital admission } & ICU & 11 & $13 \%$ \\
\cline { 2 - 4 } & Inpatient & 73 & $87 \%$ \\
\hline Hospital admission duration & Mean \pm SD & $1.15 \pm 0.47$ \\
\hline Duration (days) & Range & $1-2$ \\
\hline
\end{tabular}

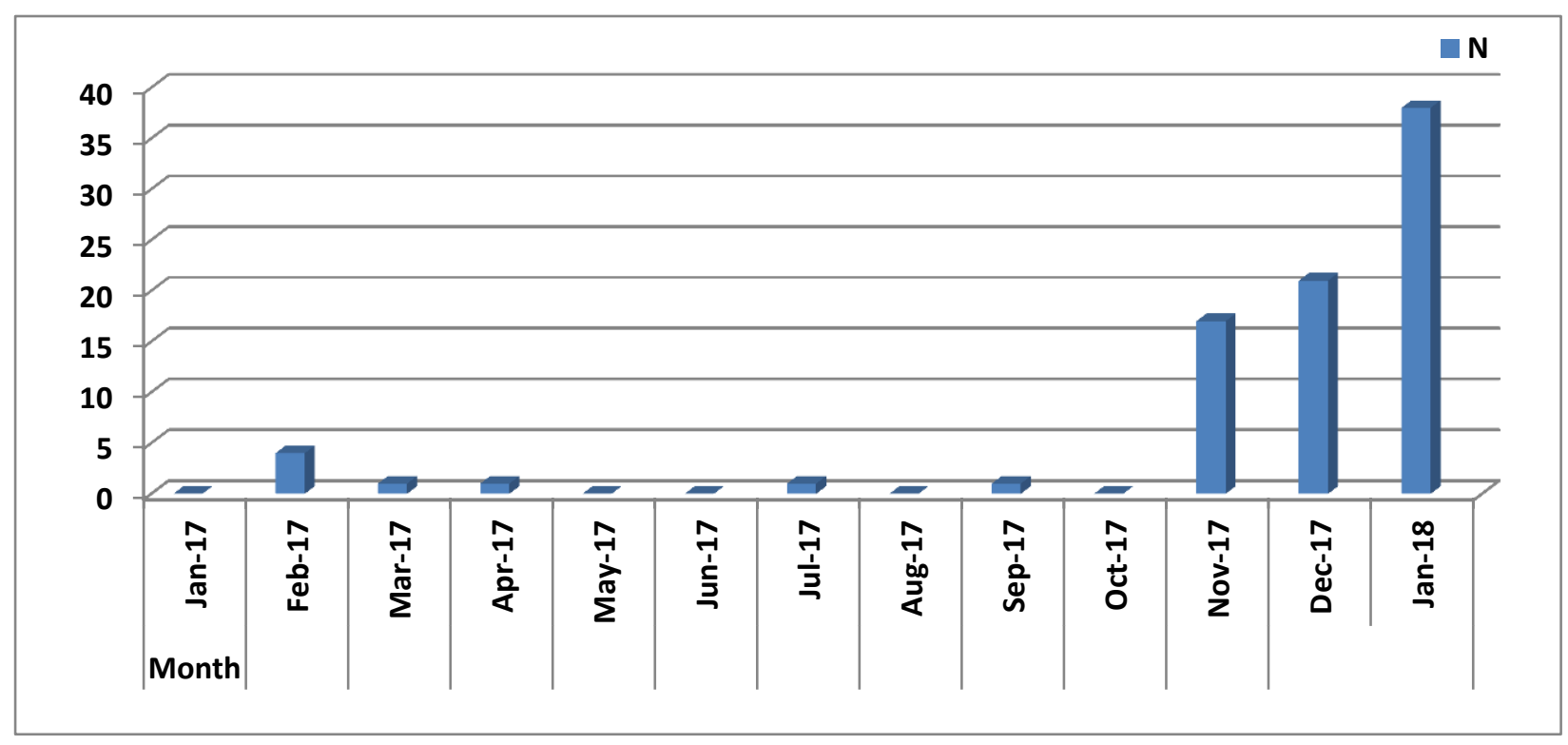

Figure (1): Bar chart showing distribution of patients during the period of study. 


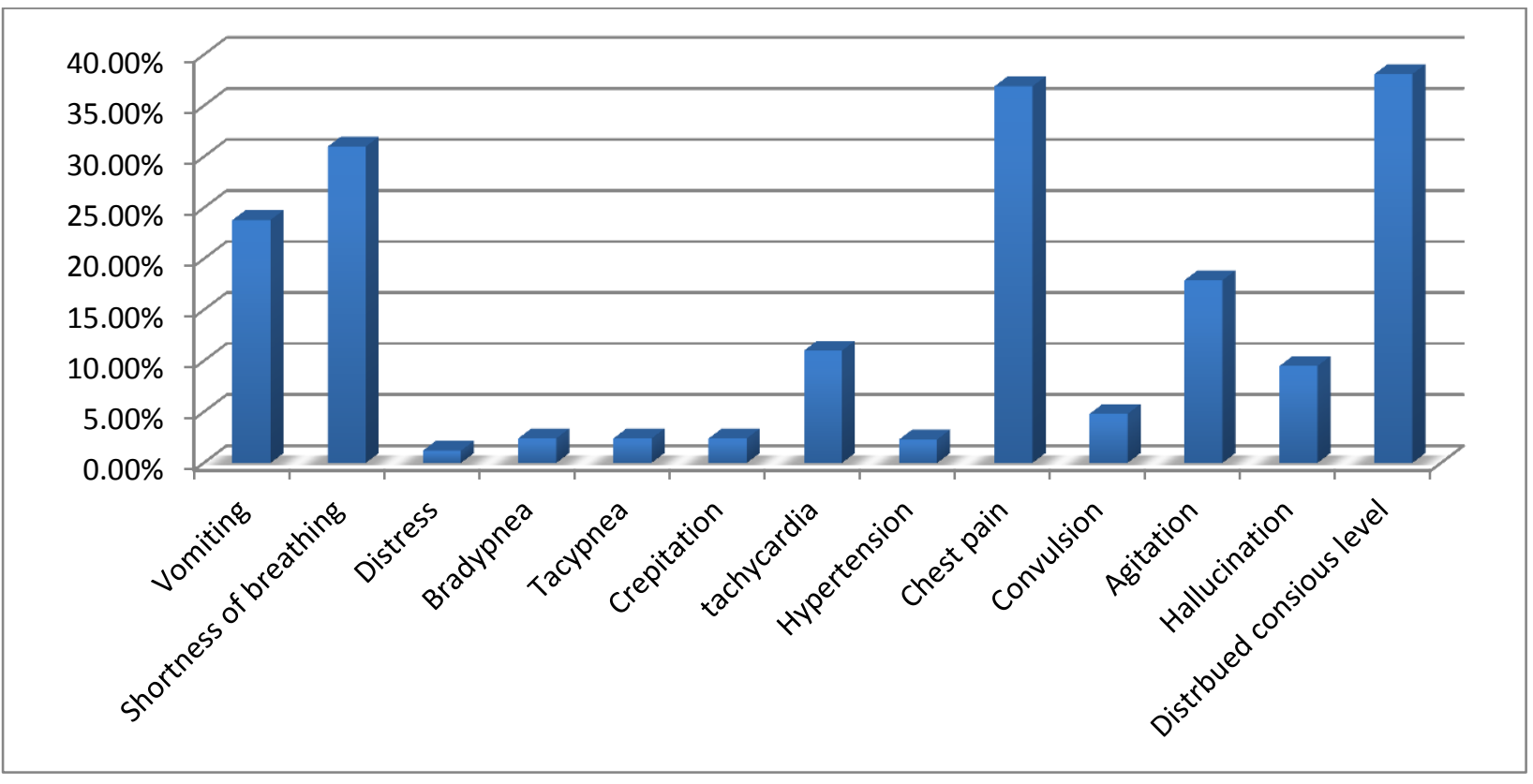

Figure (2) Bar chart shows percentage of clinical manifestations among studied patients

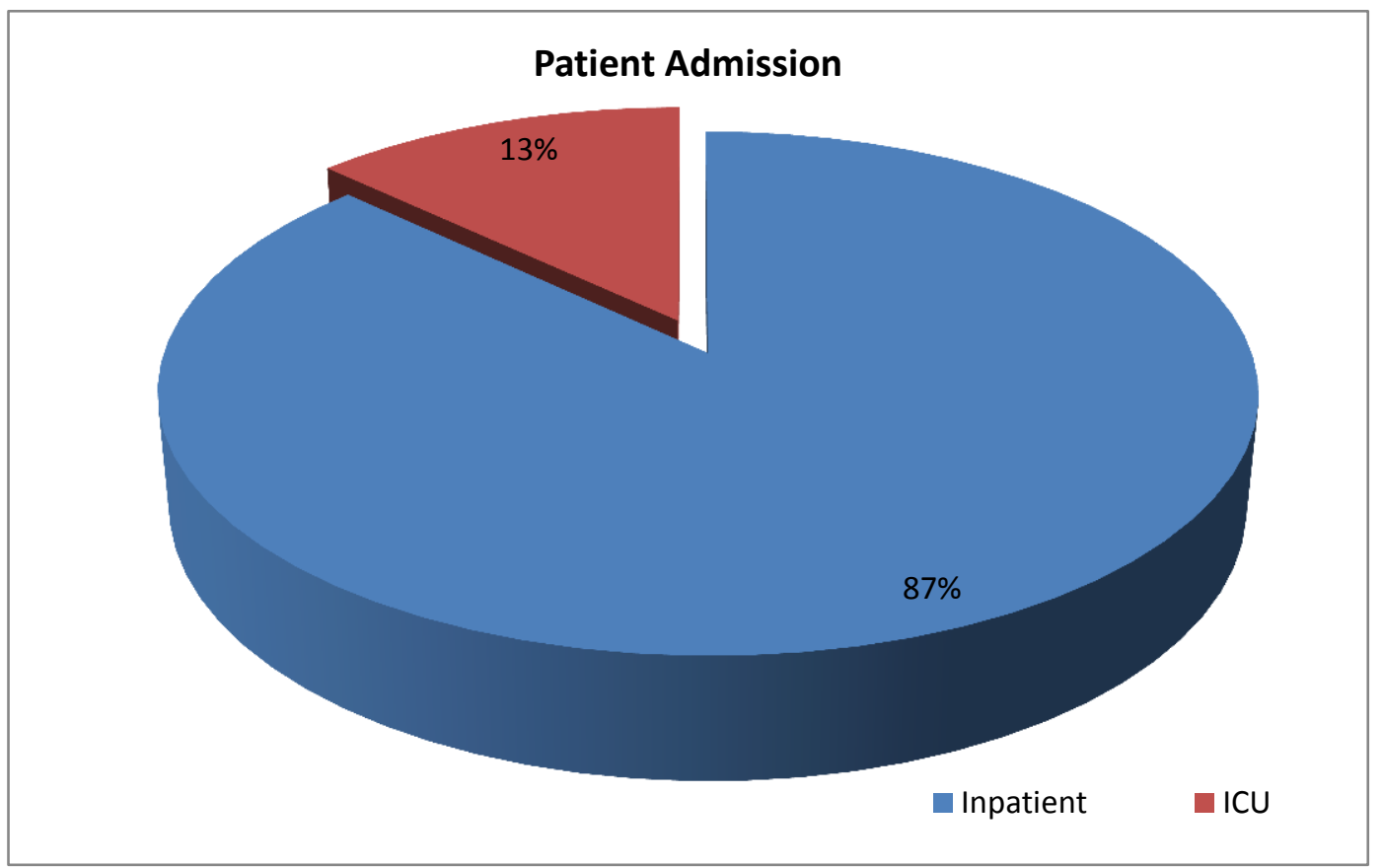

Figure (3): Pie chart showing hospital admission of studied patients

\section{Discussion}

The newly emerged designer drug "strox" made its apparition in the Egyptian street market over the last 2 years with modest cost of almost 30 Egyptian Pound for 2 joints (2-3 US\$); hence increasing its propagation and found its popularity among abusers. This was associated with increased number of patients presented to poison center with limited knowledge about its structure and possible complications secondary to its exposure. This study propagated to outline the pattern of strox toxicity and trying to explain that pattern in light of its possible structure.

In the present study; the earliest reported cases of strox intoxication started during February 2017 but there was observed increase in the number of cases during November 2017 till end of January 2018.

Substance abuse rates in Egypt have hit $10 \%$, or double the global average. The new era has witnessed the introduction of new psychoactive drugs was aiming to escape drugs of abuse detection and provision of euphoria looked for by drug abusers. The speed at which Strox use is spreading has posed a new challenge; this is due to its cheap price comparing to hashish beside powerful effect which is up to 100 times than natural marijuana (Sobh and Sobh, 2018 \&Abdelregal and Gabrah, 2020). 
"Social tolerance and acceptability to natural cannabis in Egypt encourage abuse of its synthetic potent analogues. Moreover, strox is easily to be synthesized that led to its availability with low prices in comparison with cannabis. Furthermore, the standard toxicology screens could not identify strox users whereas natural cannabis would be traced" (Sobh and Sobh, 2018).

The mean age in the current study was $25 \pm 9.8$ years. Almost all patients, except one, were male. This was in agreement with Yassa and Badea (2019) who found that male abuse was highly significant when compared with the female abuse and the most critical age of abuse was between 21 to 30 year old. In general men are more likely than women to use almost all types of illicit drugs (National Institute on Drug Abuse, 2020).

In the current study; acute strox intoxicated patients presented to PCC-ASU with a wide variety of manifestations including neurological manifestations (disturbed conscious level, hallucinations, agitation and convulsion), cardiovascular and respiratory manifestations (chest pain, shortness of breathing beside high A-a gradient) and gastrointestinal manifestation in the form of vomiting.

The diversity of the clinical presentation is forcing the clinical toxicologist to rely on the clinical picture of the abusers in addition to the traditional drug screen. This is due to alterations of the basic chemical structure of abused substances create an entirely new drug no longer regulated by current laws and an ever-changing profile of clinical effects (Nelson et al., 2014).

The depressant effect observed in this series in the form of disturbed conscious level could be explained by the inhalation of xylene added to Strox preparations. Xylene, an aromatic hydrocarbon evaporates and burns easily, of high liposolubility, is known for its central nervous system depressant effect, once absorbed by inhalation or oral route explaining the rapid occurrence of coma. Xylenes, because of their lipophilic properties, are rapidly absorbed by all routes of exposure, rapidly distributed throughout the body, and quickly eliminated in exhaled air. Xylene is one of the most widely produced and extensively used as a solvent in the rubber, printing and leather industries. It is also used as a thinner for paints, cleaning agent and in varnishes. Following oral route, this depressant effect is delayed as it was noticed in the 2 years old child in this series (Kandyala et al, 2010). The rapid short lived effect is related to its rapid metabolism and elimination from the body. Xylene is totally eliminated from the body less than 24 hours (Langman, 1994).

The dizziness, nausea and vomiting and other neurological manifestations are reversible.

Other effects include chest pain and dyspnea due to strong irritating effect and pulmonary congestion (Kandyala et al, 2010). The complaints of shortness of breath (39.2\%) and chest pain (37\%) of a large percentage of patients were as well attributed, at least partly, to Xylene. Focal areas of intra-alveolar haemorrhage and pulmonary edema with severe lung congestion were seen with high acute exposure. Rajan, and Malathi (2014) described a decreased pulmonary function and dyspnea among histology technicians chronically exposed to xylene in the laboratory. Cardiovascular effects such as flushing, palpitations and chest pains were as well seen among the exposed histology technicians. Irregular heartbeats, documented in our series, as the transient atrial fibrillation observed in one patient, have been reported as well by Rajan and Malathi (2014) in their studies. These clinical pathological findings explain hypoxemia and elevated alveolar arterial oxygen gradient observed in the patients of the current study. Exposure to xylene vapors is responsible as well to nausea and vomiting frequently noted in our study (Rajan, and Malathi, 2014).

MDMA (3, 4-methylenedioxy-methamphetamine) is a synthetic illicit drug usually is used for its euphoric effect and increased alertness It is traditionally taken orally, but it can be smoked as a powder as in Strox smoking abuse to attain rapid high. MDMA is very often smoked, especially by young people (Budzynska et al., 2018). Its oral effect starts within $20-30$ minutes, and last up to 7 hours, but may start immediately following inhalation (Kinner and Degenhardt, 2008 \& Couper and Logan, 2014). It has the same physical effects as other stimulants such as cocaine and amphetamines including tachycardia, hypertension, decreased appetite, and increased energy. Its other effects documented in our patients are confusion, irritability and agitation. Being a stimulant of the central nervous system (CNS), MDMA possesses hallucinogenic properties described as an increased sensory awareness. MDMA effects were evident in strox intoxicated cases in the current study with variable intensity.

Anti-cholinergic, preferentially trihexyphenidyl, has been indiscriminately used in prison settings, and using it recreationally by crushing it into powder and smoking it with tobacco (Pierre, 2019). In addition to its euphoric effect, trihexyphenidyl may ease depression making it drug of abuse amongst adolescents and prisoners using it either orally or by smoking it as a powder mixed with tobacco (Torrents et al., 2018 \& Pierre, 2019), however, in toxic doses it may induce hallucinations, aggression, delirium, coma and death (Pierre, 2019). Trihexyphenidyl detected in Strox packages is partly responsible for the frequent hallucinations observed in the patients of this current study.

It has been assumed, according to literature, that Strox contains psychoactive substances including hyoscine, atropine-like substances (probably atropa belladonna), hyosciamine, ketamine and or synthetic cannabinoids (Sobh and Sobh, 2018).

Ketamine was suggested as an important ingredient as the overdose might produce a picture of tachycardia, hypertension, hallucinations, vomiting and respiratory distress (Orhurhu et al., 2020); actually a picture like that described in our series. However, Ketamine is much more expensive than the price of strox sachets beside the effects of ketamine after its smoking tend to be relatively minimal compared with consuming it in other ways like; oral and injection and 
its taste especially unpleasant by smoking (Dillon et al., 2003). In addition, gas chromatography analysis could not confirm its presence of the parent compound in purchased Strox samples or in seized sachets in possession of patients.

Synthetic cannabinoids which are, typically, full agonists at the cannabinoid $\mathrm{CB}_{1}$ and $\mathrm{CB}_{2}$ receptor, and therefore considerably more potent than natural cannabis and may have correspondingly more serious psychological effects. There are various adverse physical health effects have been identified following synthetic SCs use, including tachycardia, myocardial infarction, seizures. Small number of case series described poor coordination, sedating effects, confusion and impairment of motor skills as clinical effects of SC (Akram et al., 2019). These pictures similar to findings in the current series but SC couldn't be identified by gas chromatographic analysis of obtained strox samples.

There are over 240 SCs under different brand names. One considerable problem for analysis of SCs is the fact that many compounds are very similar in structure and not all are controlled (Helander et al., 2014). These compounds have the exact same mass, the same fragmentation pattern, and similar retention times. Ingested amounts of SCs are usually in the low milligram range, resulting in very low concentrations in biological media which need very sensitive instrumentation, beside pure substances of new SCs and metabolites are often unavailable (Oiestad et al., 2013\& Helander, 2017).

Drugs of abuse commonly used in smoking include cannabis, datura, opium, crack cocaine, heroin, synthetic cannabinoids, phencyclidine, methamphetamine, and dimethyl tryptamine in addition to solvents as xylene, MDMA and trihexyphenidyl. Profile of abuse is persistently changing to suit the abuser desire of euphoria, cheerfulness and satisfaction. We are expecting to witness the introduction of new chemicals and drugs consumed in different routes to satisfy abusers craving, in addition to risk of new short and long term complications. Monitoring drug abusers for withdrawal maintenance, or management of acute drugs overdose should consider the clinical presentation, en premier lieu, in addition to conventional analytical drug screen.

\section{Conclusion}

Patients with a history of Strox smoking presented with transient coma, hallucinations, impaired ventilation attributed to impaired ventilation / perfusion, pulmonary congestion and or edema. Some of the patients complaining of chest pain had ECG evidence of myocardial ischemia. The supportive treatment is very important in case of strox toxicity. The displayed picture was due to a mixture of xylene, MDMA, and the central anticholinergic trihexiphenidyl. The picture was confirmed by gas chromatography which confirming the presence of these compounds in seized tobacco or marjoram based sachets.

\section{Recommendations}

Further studies on the clinical cases supplemented by animal experimental studies and
Chromatographic (HPLC-GCMS) analysis for patients' samples and pure form.

\section{Conflict of interest}

No conflict of interest declared by authors.

\section{References}

Abdel-regal E., and Gabrah R., (2020): prevalence of new psychoactive substances use at https://clinicaltrials.gov/ct2/show/NCT0369541 9\#contactlocation

Abass M., Hassan M., Abd Elhaleem M., Abd Elaziz H. and AbdAllah R. (2017): Acute Toxicity of a Novel Class of Hallucinogen "Voodoo" (Clinical and Experimental Study), Ain Shams Journal of Forensic Medicine and Clinical Toxicology Jan 2017, 28: 62-71.

Akram H., Mokrysz C., and Curran V., (2019): What are the psychological effects of using synthetic cannabinoids? A systematic review, Journal of Psychopharmacology 2019, Vol. 33(3) 271-283, DOI: 10.1177 / 0269881119826592 journals. sagepub.com/home/jop

Aldlgan A. (2016): Chromatographic analysis and survey studies to evaluate the emerging drugs of synthetic cannabinoids in Scotland and Saudi Arabia. PhD thesis.at http://theses.gla.ac. uk/ 7579/

Budzynska, B., Wnorowski, A., Kaszubska, K., Biala, G., Kruk-Słomka, M., Kurzepa, J., and BoguszewskaCzubara, A. (2018). Acute MDMA and Nicotine Co-administration: Behavioral Effects and Oxidative Stress Processes in Mice. Frontiers in behavioral neuroscience, 12, 149. doi: 10. 3389/ fnbeh. 2018. 00149

Couper F. J. and Logan B. K., (2014): Drugs and Human Performance Fact Sheets, Methylenedioxymethamphetamine (MDMA, Ecstasy), National Highway Traffic Safety Administration, p 67- 71.

Dillon P., Copeland J., and Jansen K., (2003): patterns of use and harms associated with non-medical ketamine use, Drug and Alcohol Dependence, Volume 69, Issue 1, 24 January 2003, Pages 23-28.

Helander A (2017): Synthetic Cannabinoid Receptor Agonists (Spice) as New Recreational Psychoactive Substances, Handbook of Cannabis and Related Pathologies (pp. 839-847).

Helander A, Bäckberg M, Hultén P, Al-Saffar Y, and Beck O (2014): Detection of new psychoactive substance use among emergency room patients: results from the Swedish STRIDA project. Forensic Science International.52: 618-624.

Kandyala R., Sumanth R., and Saraswathi R. (2010): Xylene: An overview of its health hazards and preventive measures; journal of Oral and Maxillofacial Pathology: JOMFP; 2010; 14(1):1-5. Doi: 10.4103/0973-029X.64299.

Kinner S. and Degenhardt L., (2008): Crystal methamphetamine smoking among regular ecstasy users in Australia: increases in use and associations with harm, Drug and Alcohol Review (May 2008), 27, 292 - 300. 
Langman J.M. (1994): Xylene: Its toxicity, measurement of exposure levels, absorption, metabolism and clearance, Pathology, 26:3, 301-309, DOI: 10.1080/00313029400169711

National Institute on Drug Abuse (2020): Sex and Gender Differences in Substance Use, https://www.drugabuse.gov/publications/researc h-reports/substance-use-in-women/sex-genderdifferences-in-substance-use on 2021, January 7

Nelson M.E., Bryant S.M., and Aks S.E., (2014): Emerging Drugs of Abuse, Emergency Medicine clinic, Volume 32, Issue 1, Pages 128, DOI: https://doi.org/10.1016/ j. emc. 2013.09.001

Øiestad EL, Johansen U, Christophersen AS et al., (2013): Screening of synthetic cannabinoids in preserved oral fluid by UPLC-MS/MS. Bioanalysis. 5(18): 2257-2268.

Orhurhu V.; Claus L., Rishik Vashisht R., and Cohen S., (2020): Ketamine Toxicity, StatPearls Publishing LLC, at https://www.ncbi.nlm.nih. gov /books/NBK541087/ last updated May 22, 2020.

Pierre Joseph M. (2019): Abuse of psychiatric medications: Not just stimulants and benzodiazepines. Current Psychiatry. 2019 January; 18(1):10-16,21-24,26,38
Rajan, T S., and Malathi, N. (2014): Health hazards of xylene: a literature review. Journal of clinical and diagnostic research: JCDR, 8(2), 271-274. doi:10.7860/JCDR/2014/7544.4079

Sobh H. and Sobh Z., (2018): Strox: Novel Synthetic Cannabinoids) in Egypt: Medical and Legal Challenges at https://www.researchgate.net /publication /334974503_ Strox_ Novel_ Synthetic_Cannabinoids_ in__Egypt__Medical_ and_Legal_Challenges

Torrents R., Francois J., Annie K., Patrice H., Kenneth SH., Christian L., Nicolas S., and Sami S., (2018): Misuse of Trihexyphenidyl (Artane) on Réunion Island, Journal of Clinical Psychopharmacology: June 2018 - Volume 38 Issue 3 - p 250-253 doi: 10. 1097/ JCP. 0000000000000882

Wilson-Hohler M., Fathy W.M. and Mozayani Z., (2016): How Present Synthetic Cannabinoids Can Help Predict Symptoms in the Future, MOJ Toxicol 2016, 2(1): 00029

Yassa H. and Badea SH (2019): Patterns of drug abuse in Upper Egypt: cause or result of violence? Egyptian Journal of Forensic Sciences (2019) 9:14, https://doi.org/10.1186/s41935-019-0117-7

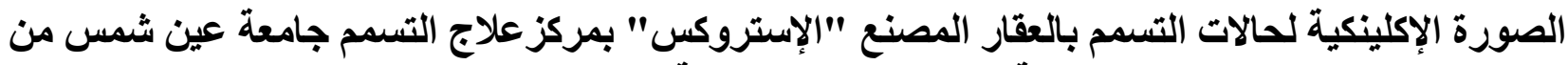

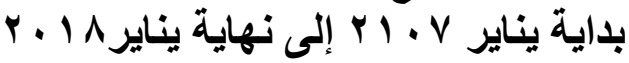

\author{
سلمى إبراهيم عبد القادر, ومحى المصرى' \\ الملخص العربى
}

المقدمة: يعتبر الإدمان واحدة من المشكلات الخطيره. تتغير الصورة الأكلينكية للإدمان على المخدرات باستمر ار لتأخذ شكلاً

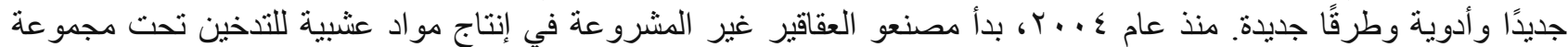

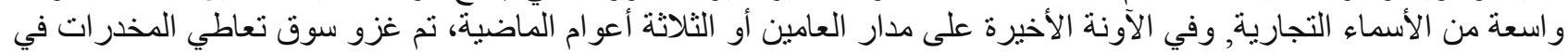

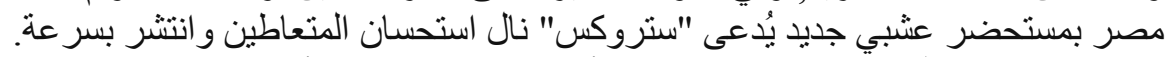

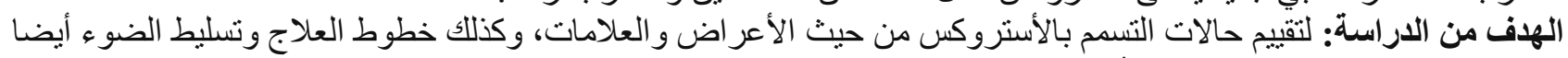

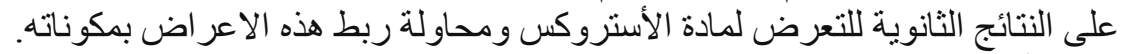

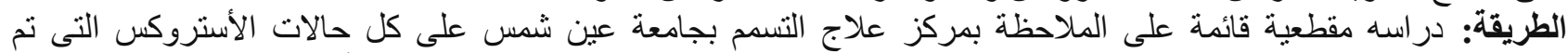

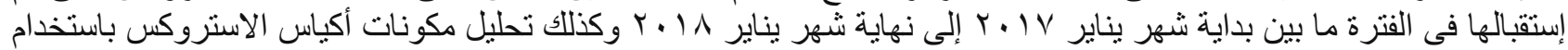
جهاز كروماتو غر افيا الغاز .

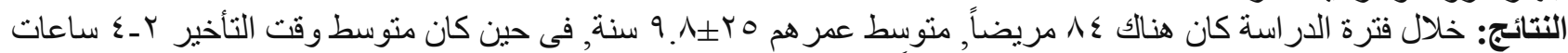

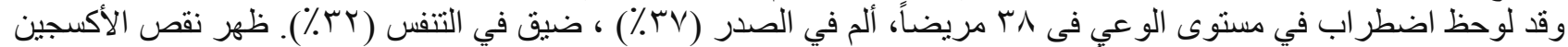

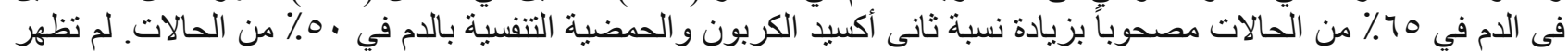

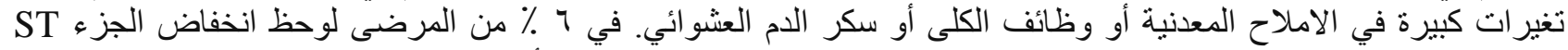

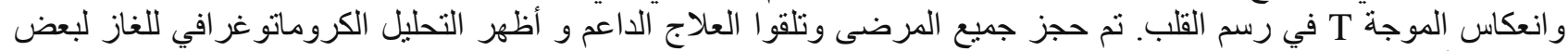

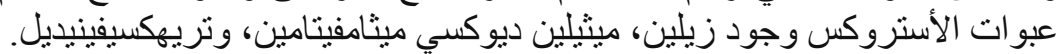

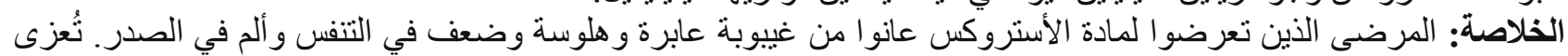

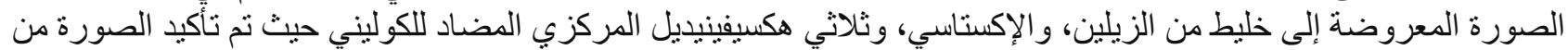

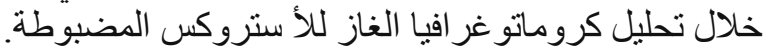

